\title{
Inter-Observer Accuracy of "Fat Pad Sign" in Determining Radiological Elbow Joint Effusion with Different Levels of Experience
}

\author{
DOAA M. FOUAD, M.D.* and NARIMAN ABOL OYOUN, M.D.** \\ The Departments of Radiology, South Egypt Cancer Institute* and Orthopedics \& Traumatology, Assiut University Hospital \\ Assiut University**
}

\begin{abstract}
Background: Joint Effusion is considered as an important indicator of many joint morbid conditions. In the sitting of trauma, fat pad displacement in lateral elbow radiograph may be the only clue of occult fractures as it is referred to elbow effusion. Likewise, it's a sign of early internal joint morbidity in many articular diseases. The classic lateral radiograph is considered as the primary choice for determining elbow joint effusion because of being simple, available and reasonable tool.
\end{abstract}

Aim of Study: The current study aimed to evaluate the inter-observer accuracy of fat pad signs of elbow lateral radiograph in detecting elbow joint effusion with the impact of observer experience on it. MRI was used as the gold standard.

Patient and Methods: The current study is a descriptive validation study in which 52 patients were included prospectively in it. Inclusion criteria were positive elbow effusion by MRI with available lateral elbow radiograph within 3 days of the MRI study. Radiographs were read by 2 groups: Group I ( 2 senior radiology residents of 3 years' experience: Reader A \& B), and group II (2 radiologists with MD degree, reader C \& D). Each observer provided his readings by either proved effusion, denied effusion or asked for further evaluation. Readers were independently and blinded to the patients' clinical data.

Results: The diagnostic accuracy percentages of elbow effusion detection for each reader compared to MRI were calculated as follows: Proper detection were from 59.6\% to $61 \%$ in low experience, and $76.9 \%$ to $82.7 \%$ in high experience. Missed cases were (19\%) in low experience and (3.8\%) to $(7.7 \%)$ in high experience group. While cases needed further evaluation were $19.2 \%$ to $21.2 \%$ in low experience and in high experience were ranging from $13.5 \%$ to $15.4 \%$. Then agreement between each reader were estimated. The same level of experience showed perfect agreement, (Kappa of 0.922 and 0.965 ). While lower agreement was detected in different experience group with Kappa of 0.51 to 0.641 , which is moderate and substantial agreement.

Conclusion: The current study emphasizes that validity of radiographs in detection of elbow effusions widely varied

Correspondence to: Dr. Doaa M. Fouad, The Department of Radiology, South Egypt Cancer Institute with levels of experience. MRI is important beside lateral radiograph for detection of elbow effusion especially in low experience to avoid missed occult fractures and early morbid joint affection.

Key Words: Elbow - Effusion - Fat pad sign - Radiography - Levels of experience.

\section{Introduction}

ELBOW joint is considered as a complex joint because it is composed of three closely connected articulations: The ulno-humeral joint, the radiohumeral joint, and the proximal radio-ulnar joint [1]. These articulations allow a combination of flexion, extension, pronation, and supination of the forearm [2].

The ulna articulates with the humerus at the trochlea, which is the grooved and rounded medial articular portion of the distal humerus. The articular portion of the ulna is formed by the olecranon process proximally and by the coronoid process more distally [3].

Elbow effusion can be concomitant with trauma, rheumatoid arthritis and inflammation. Septic arthritis results from an infection in a joint space from bacteria, fungus, virus, or even parasite, is considered as a cause of effusion as well $[4,5]$.

Many previous studies had demonstrated that elbow effusions without radiographic evidence of a clear fracture represent underlying occult elbow fractures. And so, most of pediatric patients with elbow joint effusions without clear fractures gave a concern for underlying occult fracture [6,7] Despite the fact that, pediatric elbow fractures is the most common childhood fractures, its accurate detection remains challenging and sometimes it is difficult to identify $[6,7]$. This might be due to many factors such as the preponderance of radiopaque 
cartilage, the variable appearance of ossification centers during skeletal growth, subtle and occult fracture patterns [6-8]. In the same manner in cases of septic arthritis, early detection of elbow effusion is crucial to decrease joint morbidity [9].

Radiographs have been the mainstay of initial imaging of the elbow, particularly in the pediatric trauma setting. It is very imperative to improve detection of elbow effusion in order to not miss the main evidence of occult elbow fractures and other early articular disease.

Elbow effusion can be detected on lateral radiograph by the secondary elevation of pre-articular fat by synovial fluid in the olecranon, coronoid, and radial fossae $[\mathbf{1 0 , 1 2}$. Elevation of fat can be seen at the olecranon fossa which was first reported in 1954 as posterior pad sign as a sign of elbow effusion and occult elbow fracture [10]. While fat elevation in the superimposed coronoid and radial fossae referred to the anterior fat pad sign, which was described shortly thereafter. Hence the fat pad sign described the elevated anterior lucency and/or a visible posterior lucency on a true lateral radiograph of a $90^{\circ}$ flexed elbow [10,12]

The reported frequency of occult or initially missed acute fracture in pediatric patients, or undisplaced fractures with traumatic elbow effusion has ranged from $17 \%$ to $77 \%$, disputed this association, the relationship between the presence of a positive fat pad sign and an occult fracture in children has come into question in variable studies $[10,11]$

The study aimed to evaluates the accuracy of routine radiography for the assessment of elbow effusion, using MR as the gold standard. Since many imaging findings became more accurate with experience of the readers, the study also aimed to investigate the effect of observer experience on the accuracy of detection of elbow effusion by using fat pad sign.

\section{Patients and Methods}

The current study is a descriptive validation study in which 52 patients ( 28 males and 24 females) were included prospectively. The age of patients ranged between 3 to 55 years (mean 20 year). Patients were referred from trauma unit, outpatients clinics and other hospital departments to Radiology department, Assiut University Hospital. All patients referred with symptoms suggest elbow joint trauma or articular morbidity. All patients underwent both lateral elbow radiograph and MRI study of the same joint. The study was carried out between January 2018 and October 2019. The inclusion criteria of patients enrolled in the study were: Prove of elbow effusion by MRI and available lateral elbow radiograph of the same joint within 3 days of the MRI study. We exclude negative cases of elbow effusion and unavailable radiograph within two days from the MRI study. Ethical committee approval and patients consent was considered.

Effusion was diagnosed in the presence of fluid more than $3 \mathrm{~mm}$ between bone and the capsule at the level of the trochlea or the capitulum as well as in the olecranon fossa. Each observer read 52 elbow radiographs of positive elbow effusion independently and blinded to the patients' clinical data. The observers team constituted of two groups with different level of experience. Group I: Consisted of two senior radiology residents (three years' experience) and group II: Of two senior radiologists with MD degree.

Each observer provided his reading either by proved effusion, denied effusion existence or asked for further evaluation (MRI). MRI was performed at 1.5T (Achieva, Philips) multiple planes and sequences were obtained, sagittal T1 and STIR, axial STIR and T2 fat sat, and coronal T1 and T2 fat sat. [(TR/TE 3900/60), matrix 256, slice thickness 5 , interstice gap $1 \mathrm{~mm}$ and field of view $12 \mathrm{~cm}$. The results of the radiograph from the radiologists were compared with the MR study, for each patient as a gold standard for the presence of effusion.

Statistical methods: Data entry and analysis were conducted using SPSS-21 (IBM Corp. Released 2012. IBM SPSS Statistics for Windows. Armonk, NY, USA). Percent agreement focuses on the number of codes which have been considered for their right (or related) data chunks by independent coders. Although it does not account for agreement that could occur by chance (the two coders may agree on some of the codes by chance), it is simple to transparently communicate how the method is used in a study. Chi-square test was used to compare between qualitative variables. Agreement between raters in diagnosis of effusion was examined using weighted Cohen's kappa coefficient (X), Rater's response was assessed by a 3-point scale (0, No (no effusion); 1, Yes (Effusion); 2, Not Sure (for further assessment). Cohen suggested the Kappa result be interpreted as follows: Values $\leq 0$ as indicating no agreement and $0.01-0.20$ as none to slight, $0.21-0.40$ as fair, $0.41-0.60$ as moderate, $0.61-0.80$ as substantial, and $0.81-1.00$ as almost perfect agreement ${ }^{3} \cdot p$-value considered statistically significant when $p^{<0.05}$. 


\section{Results}

All readers provided their results blindly from each other results' and the MRI results (Table $1 \&$ Fig. 1).

Table (1): Baseline description of study cohort diagnosis.

\begin{tabular}{ll}
\hline Parameter & $\mathrm{n}=52$ \\
\hline Low experience: & \\
Group I:A & \\
$\bullet$ No effusion & $10(19.2 \%)$ \\
$\bullet$ Effusion & $32(61.6 \%)$ \\
$\bullet$ Need further investigation & $10(19.2 \%)$ \\
Group II:B & \\
$\bullet$ No effusion & $10(19.2 \%)$ \\
$\bullet$ Effusion & $31(59.6 \%)$ \\
$\bullet$ Need further investigation & $11(21.2 \%)$ \\
High experience: & \\
$C:$ & \\
$\bullet$ No effusion & $2(3.8 \%)$ \\
$\bullet$ Effusion & $43(82.7 \%)$ \\
$\bullet$ Need further investigation & $7(13.5 \%)$ \\
$D:$ & \\
$\bullet$ & \\
$\bullet$ No effusion & $4(7.7 \%)$ \\
$\bullet$ Need further investigation & $40(76.9 \%)$ \\
\end{tabular}

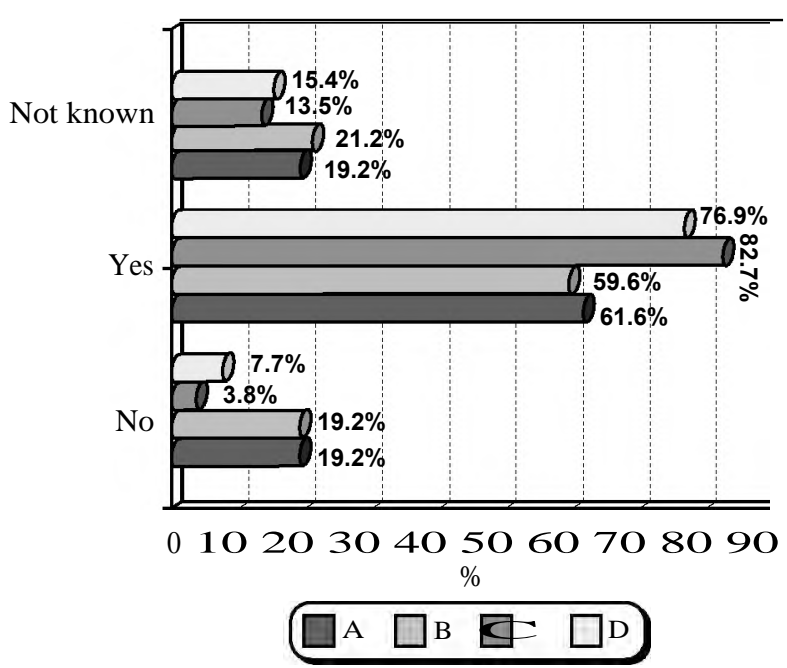

Fig. (1): Frequency of diagnostic entities among raters.

As illustrated in Table (1), Reader A: Provided proper diagnosis in 32 of 52 (61.6\% of cases), wrong results in 10 of $52(19.2 \%)$ and requested further modality in 10 of $52(19.2 \%)$. While reader B: Was right in 31 of $52(59.6 \%)$, wrong results in 10 of 52 $(19.2 \%)$ and requested further modality in 11 of 52 $(21.2 \%)$. As for the high experience, reader C: Provided proper diagnosis in 43 of $52(82.7 \%)$, wrong results in only 2 of $52(3.8 \%)$ and requested further modality in 7 of $52(13.5 \%)$, lastly reader D: Was right in 40 of 52 (76.9\%), wrong results in 4 of 52 $(7.7 \%)$ and requested further modality in 8 of 52
$(15.4 \%)$. So the different percentages of each group results are shown in Table (2).

Some cases were detected properly by the four readers as in (Fig. 2), while others were detected only by the two high experience readers, while low experience requested further evaluation as in (Fig. 3). While others were missed from all readers (Fig. 4).

Table (2): Baseline description of each group diagnosis.

\begin{tabular}{llc}
\hline & $\begin{array}{c}\text { Low experience } \\
\text { A\&B }\end{array}$ & $\begin{array}{c}\text { High experience } \\
\text { C\&D }\end{array}$ \\
\hline Range of proper detection & $61.6 \%-59.3 \%$ & $82.7 \%-769 \%$ \\
Range of missed cases & $19.2 \%$ & $3.8 \%-7.7 \%$ \\
$\begin{array}{l}\text { Range of further } \\
\text { modality request }\end{array}$ & $19.2 \%-21 \%$ & $13 \%-15.4 \%$ \\
\hline
\end{tabular}
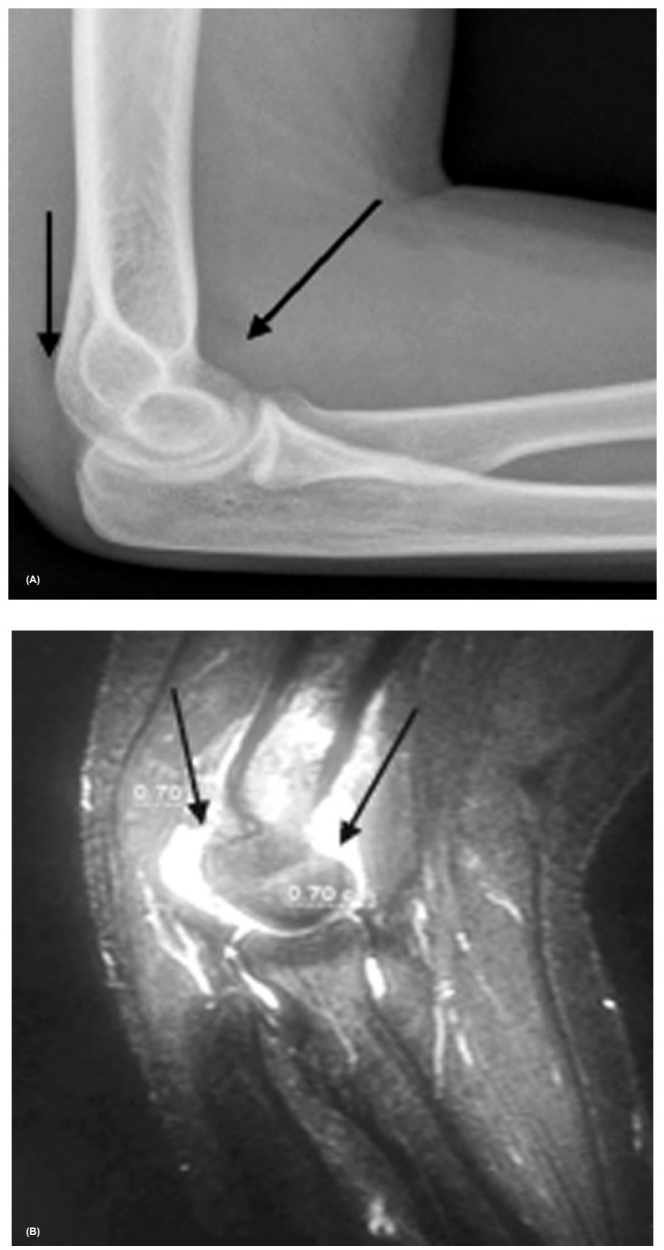

Fig. (2): [30 years old male patient, with history of trauma and elbow pain with no bone gross fractures]. Readers were blinded to the clinical data. (Fig. 2a): Lateral radiograph of the elbow joint demonstrates a positive fat pad sign with no radiographic evidence of a fracture. The anterior lucency (long arrow) represents the elevated anterior fat pad, and the posterior lucency (short arrow) represents the elevated posterior fat. Fig. (2b) MRI sagittal STAIR showed significant effusion in the anterior and posterior recesses measuring $7.0 \mathrm{~mm}$ in each recess (arrows). 

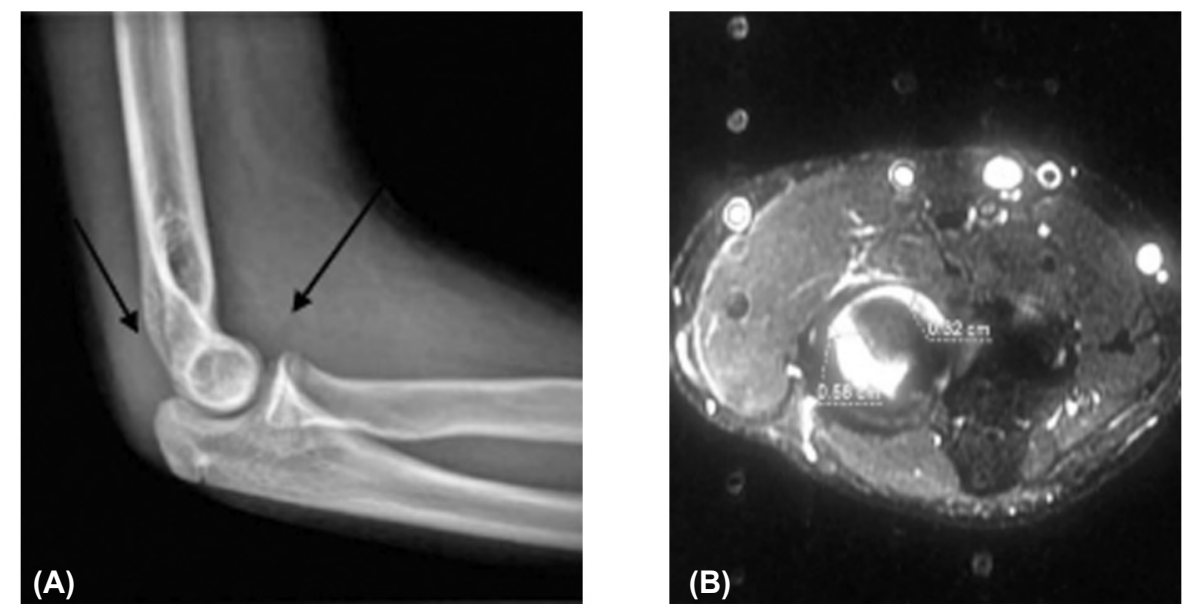

Fig. (3): [11 years old male patient, with history of trauma and elbow pain with no bone gross fractures] readers were blinded to the clinical picture. Fig.(3a): Lateral radiograph of the elbow joint demonstrates a positive fat pad sign with no radiographic evidence of a fracture. The anterior lucency (long arrow) represents the elevated anterior fat pad, and the posterior lucency (short arrow) represents the elevated posterior fat pad. Fig. (3b): MRI revealed effusion seen at the level of the olecranon in axial STIR- weighted images (Fig. 3b) measuring $3.2 \mathrm{~mm}$ in the anterior recess (white arrows) and $5.8 \mathrm{~mm}$ in the posterior recess (arrows).
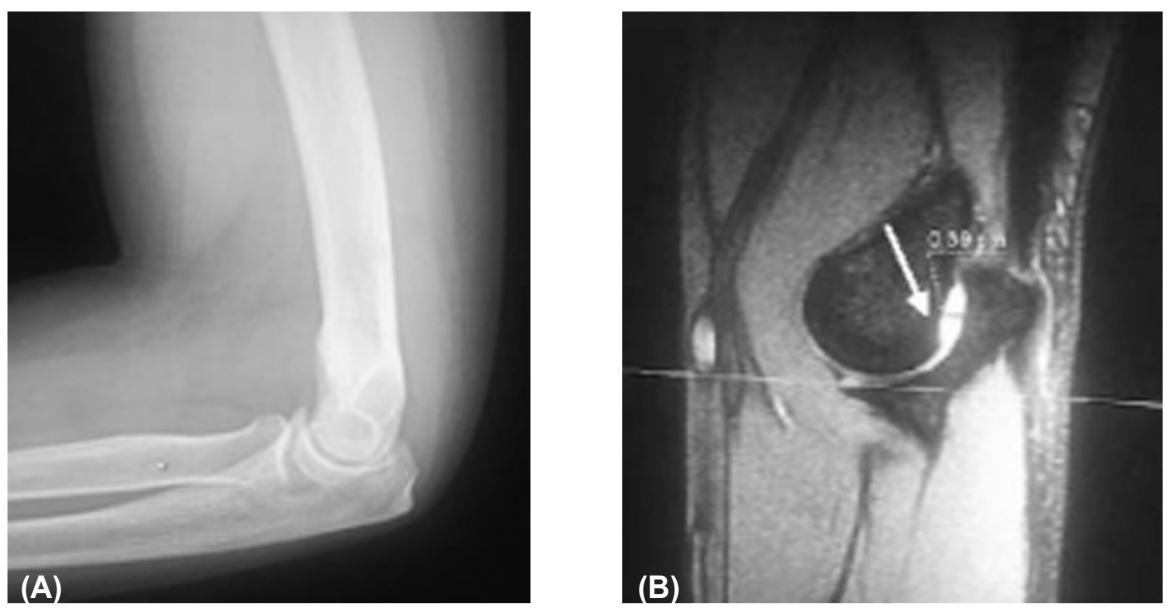

Fig. (4): [40 years old female patient, diagnosed as rheumatoid arthritis and complained of multiple joint pain included the elbow] readers were blinded to the clinical data. (Fig. 4a): Lateral radiograph of elbow in which fat pad signs either anterior or posterior were hardly detected. (Fig. 4b) minimal effusion seen in sagittal STIR-weighted images at the level of the trochlea measuring $3.9 \mathrm{~mm}$ in the anterior recess (arrows).

Regards the agreement between raters in diagnosis of effusion was examined using weighted Cohen's kappa coefficient (tc). Rater's response was assessed by a 3-point scale (Tables 3-5).

The agreement between the two low experience readers A \& B resulted in Weighted Kappa Coefficient of 0.965 (perfect agreement) in Table (3). In the same manner, the agreement between the high experience reader's C \& D were 0.922 (perfect agreement). Which means that readers from the same level of experience have perfect agreement in their results (Table 4).

While lower agreement was detected between readers from different experience level. For instance, agreement between A and the two high experience C \& D showed Weighted Kappa Coefficient of 0.538 (moderate agreement) and 0.641 (substantial agreement) respectively. The same results were detected when compared each of low experience with each of high experience as shown in (Table 5). The agreement between each reader and others were summarized in Table (6). 
Table (3): Raters agreement with others regarding diagnostic entities.

\begin{tabular}{|c|c|c|c|c|}
\hline & \multicolumn{3}{|c|}{ Rater A } & \multirow{2}{*}{ Total } \\
\hline & No & Yes & NS & \\
\hline \multicolumn{5}{|l|}{ Rater B: } \\
\hline No & $10(19.2 \%)$ & $0(0 \%)$ & $0(0 \%)$ & $10(19.2 \%)$ \\
\hline Yes & $0(0 \%)$ & $31(59.6 \%)$ & $0(0 \%)$ & $31(59.6 \%)$ \\
\hline NS & $0(0 \%)$ & $1(1.9 \%)$ & $10(19.2 \%)$ & $11(21.2 \%)$ \\
\hline Total & $10(19.2 \%)$ & $32(61.5 \%)$ & $10(19.2 \%)$ & $52(100 \%)$ \\
\hline $\begin{array}{l}\text { Weighted kappa } \\
\text { coefficient } \\
(95 \% \mathrm{CI})\end{array}$ & \multicolumn{3}{|c|}{$0.965(0.798-0.998)$} & $p<0.001$ \\
\hline Chi-square test & \multicolumn{3}{|c|}{97.759} & $p<0.001$ \\
\hline Rater C: & & & & \\
\hline No & $2(3.8 \%)$ & $0(0 \%)$ & $0(0 \%)$ & $2(3.8 \%)$ \\
\hline Yes & $8(15.4 \%)$ & $32(61.5 \%)$ & $3(5.8 \%)$ & $43(82.7 \%)$ \\
\hline NS & $0 .(0 \%)$ & $0(0 \%)$ & $7(13.5 \%)$ & $7(13.5 \%)$ \\
\hline Total & $10(19.2 \%)$ & $32(61.5 \%)$ & $10(19.2 \%)$ & $52(100 \%)$ \\
\hline $\begin{array}{l}\text { Weighted kappa } \\
\text { coefficient } \\
(95 \% \text { CI) }\end{array}$ & \multicolumn{3}{|c|}{$0.538(0.501-0.659)$} & $p<0.001$ \\
\hline Chi-square test & & 42.326 & & $p<0.001$ \\
\hline \multicolumn{5}{|l|}{ Rater D: } \\
\hline No & $4(7.7 \%)$ & $0(0 \%)$ & $0(0 \%)$ & $4(7.7 \%)$ \\
\hline Yes & $5(9.6 \%)$ & $32(61.5 \%)$ & $3(5.8 \%)$ & $40(76.9 \%)$ \\
\hline NS & $1(1.9 \%)$ & $0(0 \%)$ & $7(13.5 \%$ & $8(15.4 \%)$ \\
\hline Total & $10(19.2 \%)$ & $32(61.5 \%)$ & $10(19.2 \%)$ & $52(100 \%)$ \\
\hline $\begin{array}{l}\text { Weighted kappa } \\
\text { coefficient } \\
(95 \% \text { CI })\end{array}$ & \multicolumn{3}{|c|}{$0.641(0.513-0.751)$} & $p<0.001$ \\
\hline Chi-square test & \multicolumn{3}{|c|}{47.320} & $p<0.001$ \\
\hline
\end{tabular}

Table (4): High experience raters agreement with others regarding diagnostic entities.

\begin{tabular}{|c|c|c|c|c|}
\hline & \multicolumn{3}{|c|}{ Rater C } & \multirow{2}{*}{ Total } \\
\hline & No & Yes & NS & \\
\hline \multicolumn{5}{|l|}{ Rater D: } \\
\hline No & $2(3.8 \%)$ & $2(3.8 \%)$ & $0(0 \%)$ & $4(7.7 \%)$ \\
\hline Yes & $0(0 \%)$ & $38(73.1 \%)$ & $2(3.8 \%)$ & $40(76.9 \%)$ \\
\hline NS & $0(0 \%)$ & $3(5.8 \%)$ & $5(9.6 \%)$ & $8(15.4 \%)$ \\
\hline Total & $2(3.8 \%)$ & $43(82.7 \%)$ & $7(13.5 \%)$ & $52(100 \%)$ \\
\hline $\begin{array}{l}\text { Weighted kappa } \\
\text { coefficient } \\
(95 \% \mathrm{CI})\end{array}$ & \multicolumn{3}{|c|}{$0.922(0.804-1.000)$} & $p<0.001$ \\
\hline Chi-square test & \multicolumn{3}{|c|}{44.183} & $p<0.001$ \\
\hline
\end{tabular}

\section{Discussion}

Elbow joint consists of three highly congruent articulations; the radio-capitellar, ulno-humeral and proximal-radioulnar joints. It contains small amount of synovial fluid, formed by the lining connective tissue cells with average volume of 10$20 \mathrm{~mm}$ normally presents in asymptomatic joints [13-15]. When the amount of fluid exceeds the normal physiological amount for the joint it leads to effusion. Joints effusions are an important indicator
Table (5): Raters B agreement with others regarding diagnostic entities.

\begin{tabular}{|c|c|c|c|c|}
\hline & \multicolumn{3}{|c|}{ Rater B } & \multirow{2}{*}{ Total } \\
\hline & No & Yes & NS & \\
\hline \multicolumn{5}{|l|}{ Rater C: } \\
\hline No & $2(3.8 \%)$ & $8(15.4 \%)$ & $0(0 \%)$ & $10(19.2 \%)$ \\
\hline Yes & $0(0 \%)$ & $31(56.9 \%)$ & $0(0 \%)$ & $31(59.6 \%)$ \\
\hline NS & $0(0 \%)$ & $4(7.7 \%)$ & $7(13.5 \%)$ & $11(21.2 \%)$ \\
\hline Total & $10(19.2 \%)$ & $43(82.7 \%)$ & $7(13.5 \%)$ & $52(100 \%)$ \\
\hline $\begin{array}{l}\text { Weighted kappa } \\
\text { coefficient } \\
(95 \% \mathrm{CI})\end{array}$ & \multicolumn{3}{|c|}{$0.510(0.501-0.649)$} & $p<0.001$ \\
\hline Chi-square test & \multicolumn{3}{|c|}{38.478} & $p<0.001$ \\
\hline \multicolumn{5}{|l|}{ Rater D: } \\
\hline No & $4(7.7 \%)$ & $5(9.7 \%)$ & $1(1.9 \%)$ & $10(19.2 \%)$ \\
\hline Yes & $0(0 \%)$ & $31(56.9 \%)$ & $0(0 \%)$ & $31(59.6 \%$ \\
\hline NS & $0(0 \%)$ & $4(7.7 \%)$ & $7(13.5 \%)$ & $11(21.2 \%)$ \\
\hline Total & $10(19.2 \%)$ & $43(82.7 \%)$ & $7(13.5 \%)$ & $52(100 \%)$ \\
\hline $\begin{array}{l}\text { Weighted kappa } \\
\text { coefficient } \\
(95 \% \text { CI })\end{array}$ & \multicolumn{3}{|c|}{$0.611(0.508-0.703)$} & $p<0.001$ \\
\hline Chi-square test & \multicolumn{3}{|c|}{43.854} & $p<0.001$ \\
\hline
\end{tabular}

Table (6): Agreement between same and different level of experience.

\begin{tabular}{lcl}
\hline Agreement between & $\begin{array}{c}\text { Weighted kappa } \\
\text { coefficient }\end{array}$ & \\
\hline Same level of experience & 0.965 & Perfect agreement \\
A\&B (low) & 0.922 & Perfect agreement \\
$\begin{array}{l}\text { Same level of experience } \\
\text { C \&D (high) }\end{array}$ & 0.538 & Moderate agreement \\
$\begin{array}{l}\text { Different level of } \\
\text { experience A\& C }\end{array}$ & 0.641 & Substantial agreement \\
$\begin{array}{c}\text { Different level of } \\
\text { experience A\&D }\end{array}$ & 0.510 & Moderate agreement \\
$\begin{array}{c}\text { Different level of } \\
\text { experience B\&C }\end{array}$ & 0.611 & Substantial agreement \\
$\begin{array}{c}\text { Different level of } \\
\text { experience B\&D }\end{array}$ & & \\
\hline
\end{tabular}

for many articular and non-articular disorders. Aside from trauma, joint fluid may be increased secondary to infections, injuries, articular disease, rheumatoid or internal derangements [5].

The 'fat pad sign' is referred to radiological visualization of the extracapsular extra synovial fatty tissue which is situated at the anterior and posterior aspects of the elbow joint and can be seen on the true lateral radiograph of the flexed elbow, as a sign of an intra-articular effusion. In 
the setting of trauma, it happened due to haemarthrosis (blood in the joint) secondary to a bone fracture. This is often the only radiographic sign of a bone injury [11,12]

Radiographs are the mainstay of elbow imaging in trauma as it may be the only sign for underlying occult injury. Post-traumatic effusion without a visible bone fracture usually indicates a radial head fracture in an adult, and a supracondylar fracture of the distal humerus in a child $[5,11,12]$.

The association between joint fluid and the presence of a radiological occult fracture has been widely discussed in previous studies, and reveled the established hypothesis is that an elbow effusion following trauma referred to an indirect sign of significant bony injury. This hypothesis is supported by several studies based on the presence or absence of periosteal reaction on follow-up radiographs [10].

Many studies reported that more than $90 \%$ of displacement of the fat pad prove to have an occult fractures on either initial (at time of injury) or subsequent radiographs (at follow-up) [7,10].

Donnelly et al., [16] reported that only 54\% of cases with an isolated joint effusion with no detected fracture on initial presentation, had evidence of a healing fracture on follow-up later on. This because occult fracture can be easily missed at initial radiograph, but can be detected easily as healed fracture. Additionally, they reported that $78 \%$ of cases with occult fractures still show persistent effusions on the follow-up imaging $[7,10]$.

Hence it is crucial to consider carefully the occult fracture in cases of positive radiological fat pad sign or even suspicion of it which denoting joint effusion.

Despite this, there is still no absolute agreement on the exact percentage of occult fractures when finding a positive fat pad sign. According to the literature, it varies considerably between 17 and $89 \%$ [11]

On other hand, other authors had disputed this association and claimed that an isolated joint effusion in the absence of visualized fracture is not necessary to be concomitant with a radiographically occult fracture [7].

Aside from elbow trauma, the fat pad sign frequently occurs in non-traumatic elbow disease which caused displacement and distention of the joint capsule. It has been founded in various diseases, such as hemophilia, rheumatoid arthritis, gout, osteoarthritis, and acute pyarthrosis $[\mathbf{1 2 , 1 8 ]}$
It also detected in septic arthroplasty, synovitis and potentially olecranon bursitis $[\mathbf{1 2 , 1 9 ]}$

It can be expected to occur whenever there is distention of the joint capsule [18] .

Utilization of MRI in suspected cases of elbow effusion allowed more conclusive results for effusion detection even for minimal amount. MRI is also providing more assessment of bone marrow edema, disruption of tendons, muscles, nerves, vessels, subcutaneous soft tissue and any other soft-tissue injuries [5]

As experience had a significant impact on imaging reading, we investigated its role to improve radiograph detection of elbow effusion. In the current study the same experienced readers showed perfect agreement in their results (w Kappa of 0.922 to 0.965 ), while between different levels of experience groups were moderate to substantial agreement. This emphasizes that level of experience has an important impact on detecting the effusion by radiography. Similarly, the percentage of proper diagnosis was significantly affected by experience as it ranged from [61.6\% - 59.3\%] in low experience to $[82.7 \%-76.9 \%]$ in high level. Missed cases also showed significant variation among the two groups, low experience reported [ $19.2 \%$ ] while the high experience reported lower percentage of $[3.8 \%$ $7.7 \%$ ]. In the same manner, cases dedicated for MRI were [19.2\% to $21.2 \%$ ] in low experience while were [13.5\%-15.4\%] in high.

Hence the current study reported an overall detection of elbow effusion by radiograph varied from $60 \%-80 \%$, which is somehow satisfactory as preliminary tool and it also necessities the role of MRI in indeterminate cases [5] .

In the current study, about $15 \%$ of the missed cases attributed to lack of experience, and about $15.4 \%$ to $11.5 \%$ of MRI requests were obtained due to same cause. The variation of detection of effusion may attributed to the small amount of fluid which may be missed with low experienced radiologists. However, the accuracy of radiograph in detection of elbow effusion was assessed in many previous studies, and revealed the of superiority of MRI, but depending on MRI is also expensive, and scheduling a patient for examination is difficult [20,21]. Accordingly, we are still in need to improve the accuracy of radiograph to reduce chances of missing cases. Experience played a significant role in improving the radiograph performance and decreasing the missed cases beside the optimal technical factors and positioning for optimal detection of the fat pad sign. 
The limitations of the study were absent of relation between the size of an elbow effusion and reader's results. Another limitation of this study was the different patients age groups.

\section{Conclusions:}

Conventional lateral radiograph is still the primary modality for the elbow effusion detection. The presence of a positive fad pad sign should alert for the possibility of occult fracture or intraarticular diseases. Readers with high experience convinced a better result in radiographic accuracy of elbow effusion. MRI is still essential in suspicion when pad fat sign is not conclusive especially in low experience groups.

\section{References}

1- POLIMANTI D. and GIANNICOLA G.: Anatomy of the Elbow and How It Affects Implant Design. Elbow Arthroplasty 6: 23-36 .|DOI: 10. 1007/978-3-030-14455-5, 2020.

2- PAVI C' R., MARGETI $C^{\prime}$ P. and HNATESEN D.: Diagnosis of occult radial head and neck fracture in adults. Injury, 46: 119-24, 2015.

3- JOB N. DOORNBERG, THIERRY G. GUITTON and DAVID RING: Diagnosis of Elbow Fracture Patterns on Radiographs: Interobserver Reliability and Diagnostic Accuracy. Clinical Orthopaedics and Related Research, 47:1373-1378, 2013

4- GABRIELLE P. KONIN, LEVON N. NAZARIAN andDANIEL M. WALZ: US of the Elbow: Indications, Technique, Normal Anatomy, and Pathologic Conditions. Radio. Graphics, 33: 125-147, 2013.

5- GINA M. ALLEN and ROWENA JOHNSON: Radiographic / MR Imaging Correlation of the Elbow. Magnetic Resonance Imaging Clinic, 27: 587-599, 2019.

6- MATTHEW A. ZAPALA, KRISTIN LIVINGSTON, DANIAL BOKHARI, ANDREW S PHELPSESSE L. COURTIER, COLLIN MA, YOUNGHO SEO and JOHN D: Improved diagnostic confidence and accuracy of pediatric elbow fractures with digital tomosynthesis. Pediatric Radiology 1-8, doi.org/.1007/s00247-019-045485, 2019.

7- IYER R.S., THAPA M.M., KHANNA P.C. and CHEW F.S.: Pediatric boneimaging: imaging elbow trauma in children a review of acute and chronic injuries. AJR. Am. J. Roentgen, 198: 1053-1068, 2012.

8- PUDAS T., HURME T., MATTILA K. and SVEDSTRÖM E.: Magnetic resonance imaging in pediatric elbow fractures. Acta. Radiol., 46: 636-644, 2005.
9- PETER PATITSAS, RICHARD DAVIS and ROBERT STRONY: Point-of-Care Ultrasound-Directed Evaluation of Elbow Effusion Clinical Practice and Cases in Emergency Medicine, 3: 268-288, 2019.

10- O'DWYER, HELENA, O'SULLIVAN, PAUL, FITZGERALD, DESMOND, LEE, MICHAEL J., McGRATH, FRANK, LOGAN and MARK P.: The Fat Pad Sign Following Elbow Trauma in Adults: Its Usefulness and Reliability in Suspecting Occult Fracture. Journal of Computer Assisted Tomography, 28: 562-565, 2004.

11- JOSEPH R. ENGLAND, JORDAN S. GROSS, ERIC A WHITE, DAKSHESH PATEL JASMIN T. ENGLAND and PHILLIP M.: Detection of Traumatic Pediatric Elbow Joint Effusion Using a Deep Convolutional Neural Network AJR, 211: 1-8, 2018.

12- AL-AUBAIDI Z. and TORFING T.: The role of fat pad sign in diagnosing occult elbow fractures in the pediatric patient: a prospective magnetic resonance imaging study. J. Pediatr. Orthop., 21: 514-9, 2012.

13- KONIN G.P.: US of the elbow: Indications, technique, normal anatomy and pathologic conditions. Radiographics 33: $125-147,2013$.

14- JEAN I.H., SANCHEZ-SOTELO J., AN K.N. and MORREY B.M.: The contribution of the coronoid and radial head to the stability of the elbow. J. Bone. Joint. Surg. Br., 94-B: 86-92, 2012.

15- MARIO PADRÓN, EUGENIE SÁNCHEZ, VICTOR N. and CASSAR PULLICINO: Elbow Measurements in Musculoskeletal Radiology 301-330. doi.org/10.1007/9783-540-68897-6, 2019.

16- DONNELLY L.F., KLOSTERMEIER T.T. and KLOSTERMAN L.A.: Traumatic elbow effusions in pediatric patients: Are occult fractures the rule? AJR., 171: 243245, 1998 .

17- MAJOR N.M. and CRAWFORD S.T.: Elbow effusions in trauma in adults and children: is there an occult fracture? Am. J. Roentgenol., 178: 413-418, 2002.

18- GOSWAMI G.K.: The fat pad sign. Radiology 222: 419-420, 2002.

19-FRANK FLOEMER, WILLIAM B. MORRISON, GEORG BONGARTZ and HANS PETER LEDERMANN: MRI Characteristics of Olecranon Bursitis AJR., 183: 29-34, 2004.

20- DANIEL R. WENZKE: MR imaging of the elbow in the injured athlete. Radiologic Clinics, 51: 159-213, 2013.

21- FRITZ R.C., STEINBACH I.S., TIRMAN P F. and MARTINEZ S.: MR imaging of the elbow. An. update. Radiol. Clin. North. Am., 35: 117, 1997. 


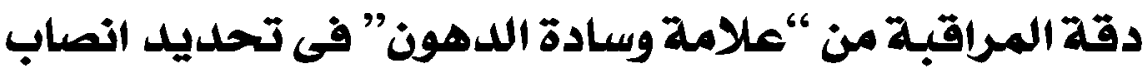

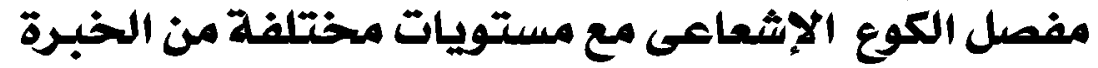

الخلفية: يعتبر الانصهار المشترك مؤشرا هاما لكثير من الأمراض المفصلية. فى حالة المدمات النفسية، قد يكون إزاحة وسادة الدهون

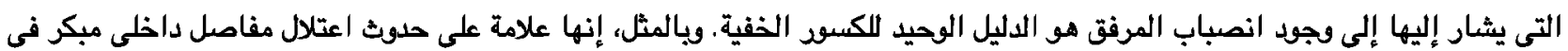

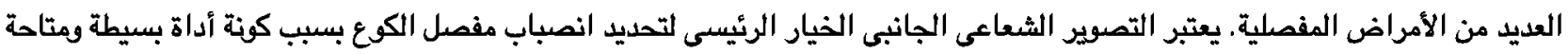

هدف البحث: قيمت الدراسة الحالية الدقة التشخيصية للأشعة فى كثف انصباب المرفق مع تأثير تجربة المراقب عليها ـ تم استخدام التصوير بالرنين المغناطيسى كمعيار ذهبى.

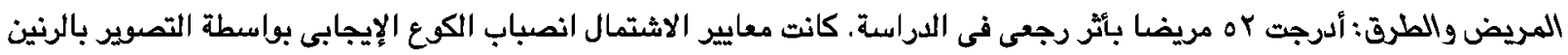

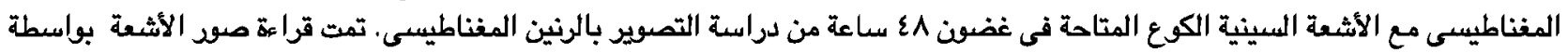

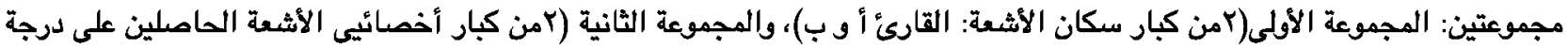

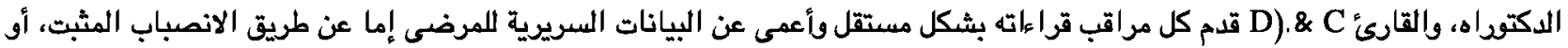
رفض الانصباب أوطلب مزيد من التقييم.

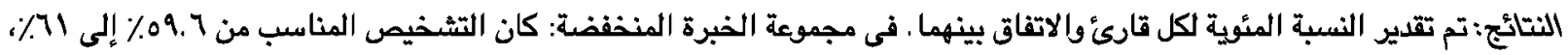

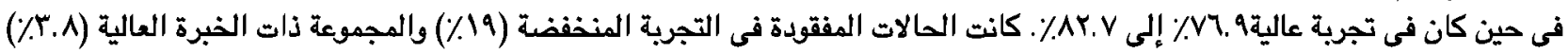

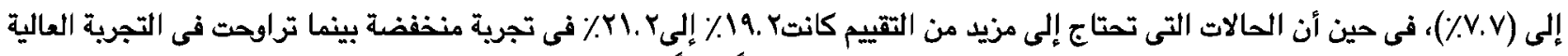

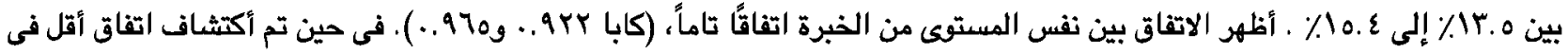

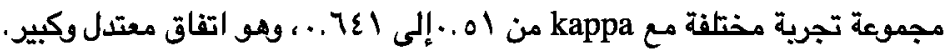

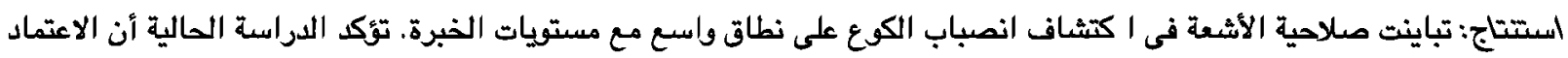

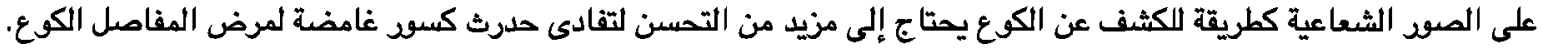

